\title{
Diamond characteristics from two distinct kimberlite types of the Churchill Diamond Project, Nunavut, Canada
}

\author{
Anetta Banas ${ }^{1}$, Pamela Strand ${ }^{2}$, Kendra Siemens ${ }^{3}$, Thomas Stachel ${ }^{4}$ \\ 1 APEX Geoscience Ltd., Edmonton, AB, Canada, \\ 2 Shear Minerals Ltd., Edmonton, AB, Canada, \\ 3 Mineral Services Canada, North Vancouver, BC, Canada, \\ 4 University of Alberta, Edmonton, AB, Canada
}

\section{Introduction}

On the Churchill Diamond Property (Nunavut, Canada, Figure 1) two discrete types of kimberlite have been discovered that are distinct with respect to their geophysical signature, indicator mineral chemistry, petrography and diamond carrying capacity (Strand et al., 2008). To date 79 kimberlites have been located on the property including nine high interest dykes (Kahuna, Notch, PST, Jigsaw and smaller unnamed dykes). The low interest (low diamond potential) Type A kimberlites have emplacement ages between 228 and $170 \mathrm{Ma}$, the high interest (high diamond potential) Type B kimberlites have an emplacement age of 234 $\mathrm{Ma}(\mathrm{Rb}-\mathrm{Sr}$ phlogopite isochron age), determined from the Notch and Kahuna dykes. Fourier Transform Infrared (FTIR) analyses were completed on diamonds from five Type A pipes and three Type B dykes (Kahuna, PST and Notch) to determine their nitrogen contents and aggregation states.

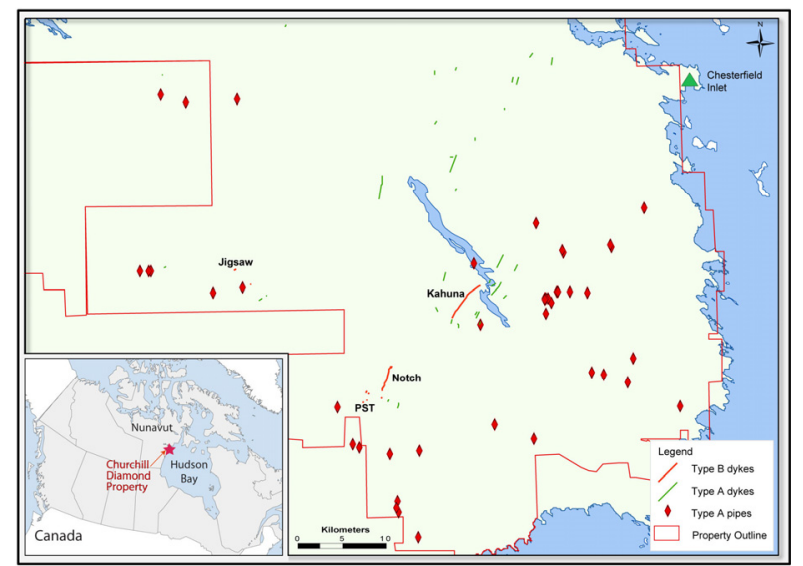

Figure 1: The Churchill Diamond property near Rankin Inlet in Nunavut, Canada.

\section{Diamond Populations}

Micro to small macro diamonds $(<0.85 \mathrm{~mm})$ recovered during exploration drilling indicate that the two types of kimberlites also have distinct diamond populations. Morphologically, diamonds from Type A kimberlite pipes are dominated by fragments, followed by octahedra and aggregates, and minor macles (octahedral twins), tetrahexahedroids and cubes. The diamonds from the Type B kimberlites (high diamond potential) are dominated by octahedra, followed by roughly equal proportions of macles, tetrahexahedroids, fragments and aggregates, and minor cubes, cubo-octahedra and pseudohemimorphic crystals (Figures 2 and 3).

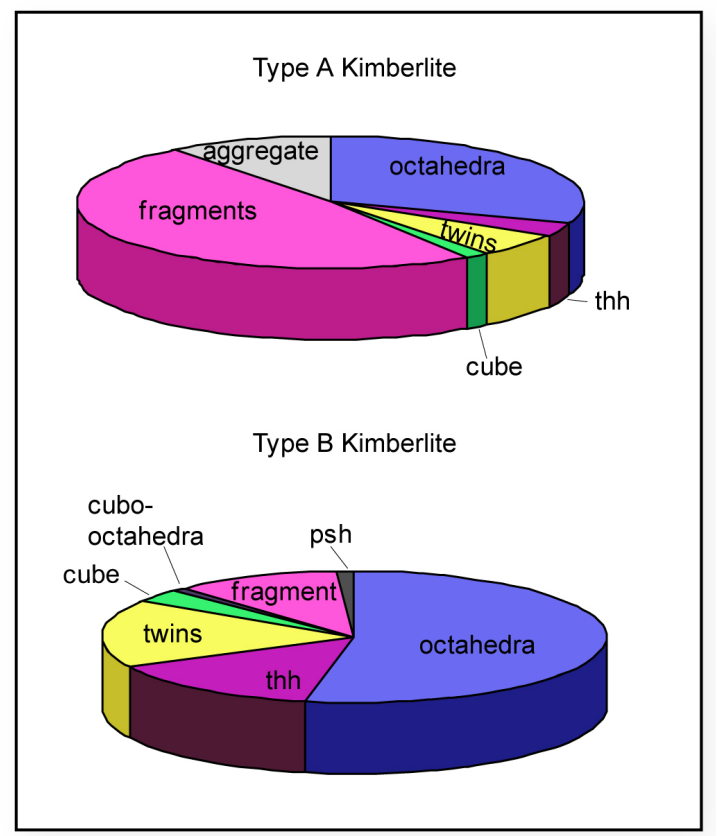

Figure 2: Diamond morphology characteristics from the Type A and Type B kimberlites (thh= tetrahexahedra, $\mathrm{psh}=$ pseudohemimorphic).

Overall, the clarity of the diamonds is very good, dominated for both kimberlite types by stones with near perfect to perfect clarity with no internal flaws (inclusions, fractures). Diamonds from both kimberlite types are predominantly colourless, followed by decreasing proportions of brown, yellow and grey.

\section{Nitrogen contents and aggregation}

The diamond populations can be further distinguished based on nitrogen content and aggregation state. FTIR analyses show that diamonds from the Type A kimberlites (7 samples analysed, Figure 4) have nitrogen contents below the limit of detection (i.e. $<10$ atomic ppm N) and thus may be classified as Type II (nitrogen-free). Diamonds from the Type B kimberlites 


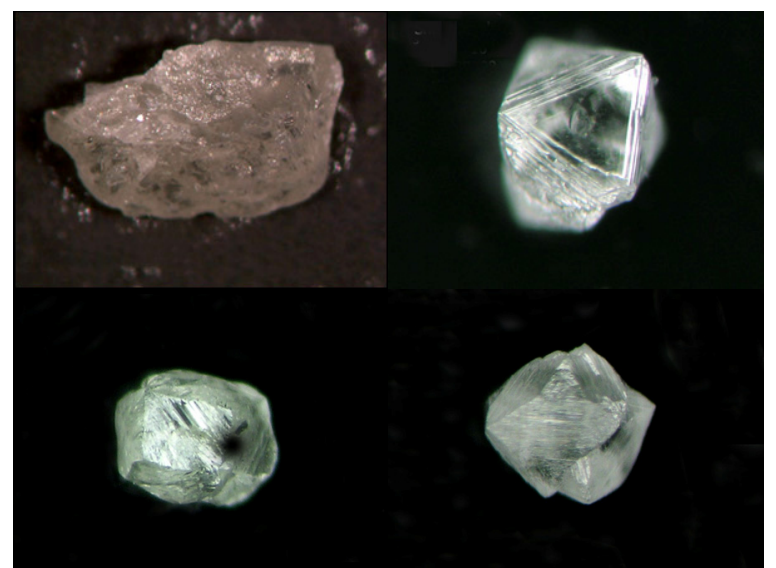

Figure 3: Common diamond shapes: from Type A kimberlite a) Diamond fragment, and type B kimberlite: b) Octahedron c) THH d) Twin

(60 samples analysed, Figure 4) have nitrogen contents ranging from below detection to 2713 atomic ppm with approximately half the sample classifying as Type II. In the Type I diamonds nitrogen aggregation varies from low (i.e. Type IaA: $>90 \%$ of nitrogen occurring in the A-center) to intermediate states (i.e. Type IaAB: nitrogen accommodated in both the A and B-centers), with maximum aggregation states of $\sim 60 \% \mathrm{~B}$. Type IaAB diamonds are significantly more abundant $(37 \%)$ than Type IaA diamonds (15\%) (Figure 4). Among the Type B kimberlites, Kahuna has the highest proportion of Type II diamonds (58\%) and the maximum nitrogen concentrations are lowest $(<250 \mathrm{ppm}$; Figure 5$)$. The diamonds from the PST and Notch kimberlites have similar abundances of Type II, IaA and IaAB and show a similar variance in nitrogen concentration (Figure 5).

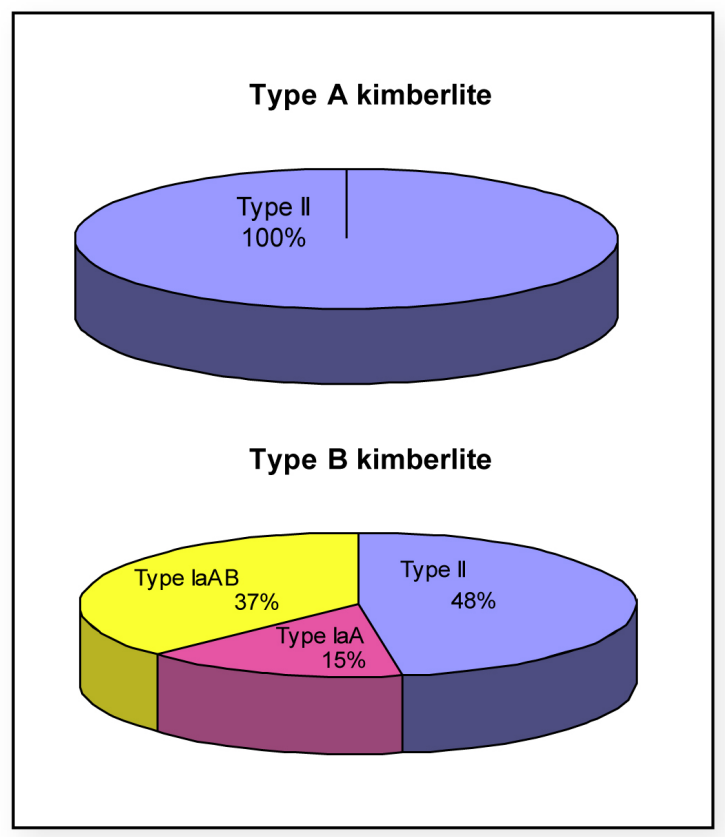

Figure 4: Classification of diamonds types based on nitrogen aggregation (Type II: no nitrogen; Type IaA: $<10 \%$ B; Type IaAB: $10 \leq \% \mathrm{~B} \geq 90$ ) for Type $\mathrm{A}$ and Type B kimberlites.
Aggregation from the A- to the B-center proceeds slowly during mantle residence and is positively correlated with nitrogen content and residence temperature (Evans and Harris, 1989). Nitrogen aggregation may be accelerated as a consequence of strain. In the diamond samples from the Type B kimberlites, nitrogen contents and aggregation states appear unrelated, with the highest nitrogen contents occurring in diamonds with low aggregation (i.e. $<10$ $\% \mathrm{~B}$; Figure 5). This observation is inconsistent with isothermal variations in nitrogen content and aggregation and suggests that diamonds were sampled over a temperature (i.e. depth) interval.

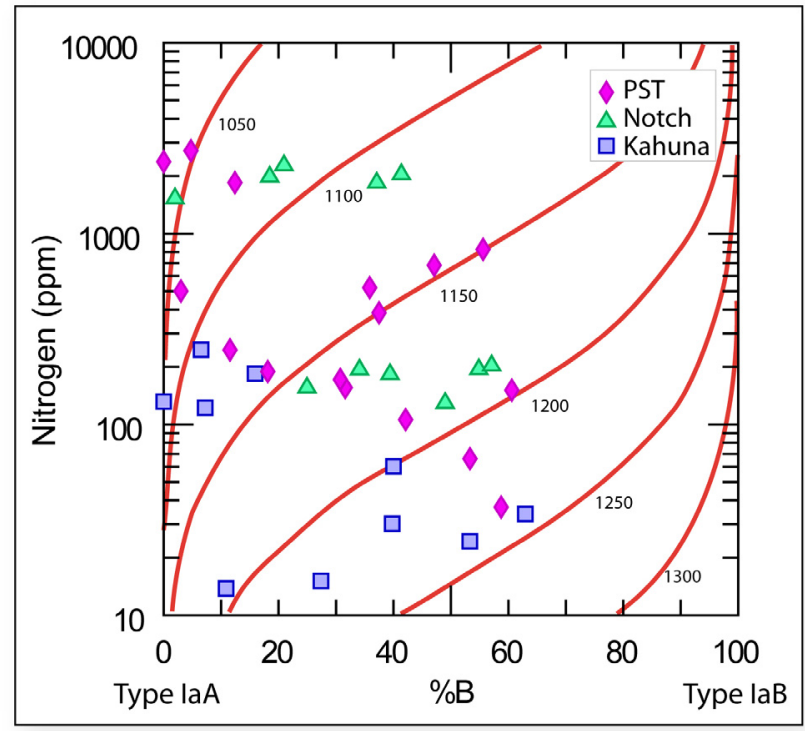

Figure 5: Nitrogen contents and aggregation states (expressed as the relative proportion of nitrogen in B-centers) for diamonds from PST (diamonds), Notch (triangles) and Kahuna (squares). Solid lines are isotherms $\left({ }^{\circ} \mathrm{C}\right)$ for a mantle residence time of $1 \mathrm{Ga}$ (after Taylor et al., 1990).

\section{Conclusions}

Significant differences in the morphology and nitrogen content of diamonds from Type A and B kimberlites suggest that the two kimberlite events sampled different diamond populations. For Type B kimberlites, different ranges in nitrogen concentrations combined with similar distributions of nitrogen aggregation states observed at PST and Notch versus the Kahuna kimberlite suggest that there is variability in the diamond populations sampled by the Type B kimberlites across the Churchill Diamond Property. At Kahuna, the presence of a Type IaAB diamonds with nitrogen contents $<100 \mathrm{ppm}$ ( 6 out of 9 ) suggests that this kimberlite preferentially tapped a deep $\left(\mathrm{T}_{\text {Nitrogen }}\right.$ $>1200^{\circ} \mathrm{C}$ ) lithospheric diamond reservoir.

\section{Acknowledgements}

We thank David Fisher from the Research Laboratories of the Diamond Trading Company for use of the spectral de-convolution software; the laboratories 
(especially SRC \& Mineral Services) for timely processing and analysis of samples and Mike Baumgartner.

\section{References}

Evans, T., Harris, J.W., 1989, Nitrogen aggregation, inclusionequilibration temperatures and the age of diamonds. In: Ross, J.,et al. (Ed.), Kimberlites and Related Rocks. Geological Society of Australia, Special Publication 14, vol. 2. Blackwell, Carlton, pp. 1001-1006.

Strand, P., Banas, A., Burgess, J., Baumgartner, M. 2008, Two Distinct Kimberlite Types at the Churchill Diamond Project. Extended Abstracts, 9th International Kimberlite Conference, $3 p$.

Taylor, W.R., Jaques, A.L., Ridd, M., 1990, Nitrogen-defect aggregation characteristics of some Australasian diamonds: time-temperature constraints on the source regions of pipe and alluvial diamonds. American Mineralogist 75 (11-12), 1290-1310. 